\title{
The association between death anxiety with spiritual experiences and life satisfaction in elderly people
}

\author{
Mina Taghiabadi ${ }^{1}$, Ali Kavosi ${ }^{2}$, Seyed Reza Mirhafez ${ }^{3}$, Mahrokh Keshvari ${ }^{4}$, Tayebe Mehrabi ${ }^{5}$
}

${ }^{1}$ M.Sc. Student, Nursing and Midwifery Care Research Center, School of Nursing and Midwifery, Isfahan University of Medical Sciences, Isfahan, Iran

${ }^{2}$ M.Sc., Department of Operating Room, Faculty Member of Neyshabur University of Medical Sciences, Neyshabur, Iran

${ }^{3}$ Ph.D., Assistant Professor, Department of Basic Medical Sciences, Neyshabur University of Medical Sciences, Neyshaur, Iran

${ }^{4}$ Ph.D., Assistant Professor, Department of Community Health Nursing, Nursing and Midwifery Care Research Center, School of Nursing and Midwifery, Isfahan University of Medical Sciences, Isfahan, Iran

${ }^{5}$ M.Sc., Nursing and Midwifery Care Research Center, Faculty of Nursing and Midwifery, Isfahan University of Medical Science, Isfahan, Iran

Type of article: Original

\begin{abstract}
Introduction: Death anxiety is a concept with greater importance among the elderly as they approach inevitability of death. Identifying the correlates of death anxiety among old people is important in order to reduce the burden of this problem. Therefore, the present study was performed with the aim to examine the association between spiritual experiences and life satisfaction with death anxiety in this stage of life.

Method: This cross-sectional study with descriptive-analytical design included 190 elderly people visiting the health and medical centers of Neyshabur city, Iran, during fall and winter, 2016. Participants were asked to complete three questionnaires including a 16-item spiritual experiences scale, life satisfaction index proposed by Wood and Shifor with 13 items, and a 27-item death anxiety scale developed by Aminpour. Analytical statistics (Spearman's correlation coefficient, Pearson's correlation coefficient) were conducted using SPSS software version 22.

Results: Fifty-eight percent of participants were in younger elderly age group with mean age of $68.18 \pm 7.13$ years and the number of men and women was the same (95). A significant positive association between spiritual experiences and life satisfaction $(\mathrm{r}=0.2, \mathrm{p}<0.05)$, a significant negative association between spiritual experiences and death anxiety $(\mathrm{r}=-0.184, \mathrm{p}<0.05)$ and a significant negative relationship between life satisfaction and death anxiety $(\mathrm{r}=-0.2, \mathrm{p}<0.05)$ was found.

Conclusion: Based on results, it seems that reducing stressors in this stage of life including reduction of death anxiety, is possible through use of spiritual experiences and increasing life satisfaction.

Keywords: Death anxiety, Spiritual experiences, Life satisfaction, Elderly
\end{abstract}

\section{Introduction}

Aging is a critical stage of life and it is necessary to put the needs and issues associated with this stage under consideration. Death anxiety is one of most important issues among this aging population since they experience the inevitability of death approaching of and it is also important for them to achieve a sense of integrity versus despair $(1,2)$. Due to the invariable nature of this stressful factor, elderly people are more likely to try to emotionally avoid this situation or to use philosophical or spiritual beliefs to help them to cope with these uncontrollable situations (3). Various studies have investigated different aspects of religiosity and effects of spirituality and religiosity on different aspects of life in elderlies. For example, a 2008 study by Ellison and Fan examined the association between

\section{Corresponding author:}

Tayebe Mehrabi, Nursing and Midwifery Care Research Center, Faculty of Nursing and Midwifery, Isfahan University of Medical Science, Isfahan, Iran. Tel: +98.3137927595, Email: mehrabi@nm.mui.ac.ir

Received: December 03, 2016, Accepted: January 22, 2017, Published: March 2017

iThenticate screening: January 21, 2017, English editing: February 09, 2017, Quality control: March 06, 2017

(C) 2017 The Authors. This is an open access article under the terms of the Creative Commons Attribution-NonCommercialNoDerivs License, which permits use and distribution in any medium, provided the original work is properly cited, the use is non-commercial and no modifications or adaptations are made. 
spiritual experiences and psychological well-being in America, and found that each unit increase in daily spiritual experiences was associated with $31 \%$ higher chance of not being distressed (4). These strongly support the hypothesis that daily spiritual experiences scale (DSES) is related to positive psychological effects and death anxiety could be influenced by spiritual experiences. On the other hand, death anxiety could be influenced by satisfaction with life, since acceptance of one's own life could influence fear of death and help the person to confront death (5). A 2005 study by Cohen and Colleagues studied the associations between death anxiety and life satisfaction with religion among certain faith traditions in Italy, and stated that life satisfaction was inversely correlated to death anxiety (6). A 2013 study by Leik also investigated the relationship between aspects of meaning in life and death anxiety among young adults. The author pointed out that the search for meaning in life was significantly associated with fear of one's own death and dying (7). Degree of life satisfaction is variable in the elderly due to some changes in the shape and function of the body and its organs with aging, which impair performance capacity and the ability to cope with the environment. These changes lead to physical and mental dependence on others (8). The ability to cope with these changes determines the success in accomplishment of a sense of integrity versus despair and satisfaction with life in elderly people (2). The population of senior citizens is increasingly growing and one of the important challenges for them is fear of death and death anxiety. This factor has a critical role in mental health maintenance among elderly people. Therefore, identification, evaluation and control of factors affecting death anxiety, is important to reduce the burden of this problem in daily life of older adults. Evidence suggest that spirituality and life satisfaction could be effective in reducing death anxiety. Spirituality is increased through years of life, and elderly people have more mature spiritual experiences. On the other hand, satisfaction with life and acceptance of one's own life could prepare old people for confronting their death. Thus, in the present study, we aimed to evaluate these variables, which are more closely related to personal and experiential aspects of life, and their association with death anxiety among elderly people.

\section{Material and Methods}

\subsection{Research design and participants}

This descriptive-analytical study was conducted during fall and winter, 2016 among elderly people visiting the health and medical centers of Neyshabur, Iran. Using quota sampling method and with assumption of $20 \%$ attrition rate, a convenience sample of 250 participants were selected and questionnaires were distributed. Of 250 subjects, 190 elderly people aged 60-93 years with no physical or mental disorder and experiencing no stressful incident within the previous year (based on score of less than 150 in Holmes and Rahe scale) were included in the final analysis.

\subsection{Instrument}

Daily spiritual experiences scale (DSES) was used to assess spirituality. This scale consists of 16 items developed by Underwood and Teresi in 2002, for multi-dimensional evaluation of spirituality. Concepts such as perceived connection with God, inner balance, fear, gratitude and forgiveness are evaluated through this scale. Using a Likert scoring system, the overall score ranges from 16.6 to 96 with higher scores indicating more spiritual experiences. The internal consistency reliability estimate with alpha coefficient was 0.91 , which is very high and it was significant. DSES scale and Allport and Ross religious orientation questionnaire were evaluated simultaneously, and results showed correlation coefficient of 0.71 between scores in both scales for all subjects, suggesting a good construct validity. In order to assess life satisfaction, life satisfaction index (LSI) revised by Wood and Shifor in 1969 was used, consisting of 13 items. A good construct validity has been reported for this scale among 75 elderly citizens in Kashan, Iran, using known-groups comparison method $(\mathrm{F}=121.66, \mathrm{p}<0.001)$. The reliability estimated with Cronbach's alpha was reported to be 0.79 . In this study, a 0-1-2 scoring system was used and the overall score ranged from 0 to 26, with higher scores indicating higher life satisfaction. Death anxiety scale consisting of 27 items was used to assess the signs of death anxiety. This scale was developed by Aminpour et al. in 2013 with 4 main components including fear of death consequences, fear of being killed, fear of punishment after death and fear of sudden death. Validity of this scale was measured in a sample of 250 subjects with mean age of 22.9 years, and validity of 0.85 was reported for 27 -item scale. In order to test the reliability of the scale for the purpose of the present study, retest method was used. Questionnaires were completed by 20 subjects of the studied population and after 2 weeks, they were asked to complete the same questionnaire again. After statistical analysis, Cronbach's alpha of 0.86 was obtained. A 5- point Likert scale is used for scoring and the sum of scores indicates the level of death anxiety (0-27 very low death anxiety, 28-44 low death anxiety, 45-63 medium death anxiety, 64-81 high death anxiety, 82-108 very high death anxiety). 


\subsection{Ethics of research}

With permission of The Ethics Committee of Isfahan Nursing and Midwifery school ((Registration code: 394720), the main investigator visited health and medical centers in certain times of the day and the aim of the research was explained, and informed consent was obtained and data was collected.

\subsection{Statistical analysis}

Analysis was performed by SPSS, 22 software package (IBM○ Corp., Armonk, NY, USA) and descriptive and analytical tests (Spearman and Pearson correlation coefficients) were used.

\section{Results}

The mean age of participants was $68.18 \pm 7.8$ years. Of participants who had informal literacy with the highest frequency in terms of education level, there were $28.9 \%$. The majority of the participants $(44.2 \%)$ were retired, $58.2 \%$ were married and were living with their family and $57.4 \%$ were of medium economic status. Based on results, the overall mean life satisfaction was $14.11 \pm 5$.9. The mean of spiritual experiences was $78 \pm 8.7$ and the total mean of death anxiety was $56.9 \pm 24.5$ (Table1). Significant inverse relationships between spiritual experiences and death anxiety $(\mathrm{r}=-0.18, \mathrm{p}=0.04)$ and between life satisfaction and death anxiety $(\mathrm{r}=-0.2, \mathrm{p}=0.002)$ were observed. In univariate analysis of variance to examine the association between spiritual experiences and life satisfaction with death anxiety, it was found that with each unit increase in life satisfaction, one-unit decrease in death anxiety occurred and with each unit increase in spiritual experiences, a mean reduction of 0.09 was observed in death anxiety.

Table 1. Mean and Standard deviation of spiritual experiences, life satisfaction and death anxiety in participants.

\begin{tabular}{|l|l|l|l|}
\hline Variable & Mean & SD \\
\hline Life Satisfaction & Women & 78.13 & 6.18 \\
\cline { 2 - 4 } & Men & 59.14 & 5.67 \\
\cline { 2 - 4 } & Total & 11.14 & 5.4 \\
\hline Spiritual Experiences & Women & 77 & 8 \\
\cline { 2 - 4 } & Men & 78 & 8 \\
\cline { 2 - 4 } & Total & 78 & 8.7 \\
\hline Death Anxiety & Women & 58.7 & 28.5 \\
\cline { 2 - 4 } & Men & 55.3 & 19.2 \\
\cline { 2 - 4 } & Total & 56.9 & 24.5 \\
\hline
\end{tabular}

\section{Discussion}

In this study, the mean spiritual experiences score was $78.04 \pm 8.7$, indicating high level of spiritual experiences among participants. This finding is in line with the results found by Skarupsk (2015) showing a high degree of spiritual experiences in studied elderly (the mean score of 5 out of 6) (19). This confirms the fact that in late life, a reorientation towards spirituality occurs and spiritual perspective becomes increasingly important, which could be due to the physical changes and also changes in the person's role in life, death of loved ones and many other outcomes associated with aging (9). The mean score of life satisfaction was $14.2 \pm 5.9$, indicating that a medium level of life satisfaction exists among participants. The results of Golshahi et al. (2014) in the city of Borujen and Hajizadeh Meymandi et al. (2012) in Yazd showed that the mean score of life satisfaction among the elderly living in Borujen was 22.43 \pm 7.23 and among elderly women in Yazd city, was $16.18 \pm 0.52$, respectively. The findings of the present study were consistent with those works which, with similar statistical population in terms of age, religion and nationality, reported a medium level of life satisfaction among participants. Erikson's theory states that aging is associated with life review phenomenon, and starts around the age of 60 and the person seeks to find meaning, significance and value in life which leads to life satisfaction (20). On the other hand, old people use coping mechanisms to overcome the problems and they are more flexible in the face of frustration, and their emotional capacity increases with age, which could lead to life satisfaction in old age (21). The mean death anxiety score was $56.93 \pm 24.5$ indicating a medium level of death anxiety among participants in the present study. In a 2016 study by Saini et al., to examine death anxiety and associated factors in elderly people in Panjab, Pakistan, it was reported that the mean score of death anxiety was $22.7 \pm 4.69$, which indicates a moderate level of death anxiety. The results of the present study are consistent with this finding, and show that death anxiety is relatively high among the elderly (22). In this study, the association between spiritual experiences, life satisfaction with death anxiety was examined to show that there are two distinct ways to successfully manage death anxiety among the elderly. As expected, 
spiritual experiences in late adulthood were effective in dealing with death anxiety. Spiritual experiences which are experimental and subjective and dependent on a person's ideology, have effects on death anxiety as an unavoidable fear. Most studies have examined the associations between religion and death anxiety, and various aspects of religiosity have been investigated. For example, a 2014 study by Henrie and Patrick stated that while a significant positive effect of religious doubt on death anxiety was seen, no significant association was found between religiosity and death anxiety. Also, in a 2011study by Dehkordi et al., a significant inverse association between death anxiety and internal religious orientation, and a significant positive relation between death anxiety and external religious orientation was observed (23). A 2013 study by Morie on 100 full-time or part-time students of psychology in Doblin University showed that no significant association existed between internal and external religious orientation and any of the variables associated with death anxiety, life satisfaction and psychological health. Also, in another study in 2010 by Azaiza et al. on elderly Arab Muslims living in Israel, religiousness was not associated with anxiety regarding death and dying (24). On the other hand, there are few studies examining the essence and content of spiritual experiences. For example, a 2014 study by Mahbub et al., investigated the link between spiritual experiences and death anxiety in hemodialysis patients and reported a negative association between death and spirituality (25). A 2006 study by Wink et al., on elderly people living in California, U.S.A, found no significant association between spirituality, either alone or in combination with belief in afterlife, and death anxiety. However, this result may have been due to inconsistency between spirituality and belief in afterlife as two distinct aspects of belief (26). In studies regarding the association between death anxiety and religion, behavioral indices and participation in religious organizations such as the frequency of attending religious rituals have been used, which could be done due to different motives and could explain the inconsistency in results across studies. But research on spiritual experiences has led to confirmative results, since the focus is primarily on personal and experimental aspects, and these experiences are stable and permanent. Considering the importance of spiritual values and skills as necessary aspects of clinical care in nursing, using the experimental aspect of spirituality and recognition, and reinforcement of this aspect in aging through controlling stressors such as death anxiety could be important among strategies in nursing care. Considering meaning and purpose in life and high self-esteem lead to less anxiety regarding death, the association between life satisfaction and death anxiety have been examined. A 2005 study by Cohen et al, with the aim to examine the association between internal and external religious beliefs, belief in afterlife, death anxiety and life satisfaction in 375 participants aged 13- 25 years in Rome (6), and in another 2009 study by Moreno et al., to investigate factors associated with death anxiety in the institutionalized and noninstitutionalized elderly in Spain, showed that life satisfaction is inversely associated with death anxiety (27). Also, a 2014 study by Satomi regarding the relation between identity and death attitude in elderly citizens in Japan, found that acceptance of one's own life, lowers fear of death and prepares the person to face death. The results of the present study are in line with these previous works and could be explained by the Erikson theory suggesting that successful resolution of integrity versus despair crisis in old age is associated with decreased death anxiety (20).

\section{Conclusions}

The results showed an inverse association between life satisfaction and death anxiety and also a direct relation between spiritual experiences and death anxiety. Considering the important role of spirituality in old age and the close relationship between nursing staff and older adults, it is suggested that spiritual experiences and higher life satisfaction are used to confront with stressors in this critical stage of life and to enhance the quality of life. Further studies regarding the effects of different aspects of religion, spirituality and quality of life on experiences during old age are warranted.

\section{Acknowledgments:}

This study (Registration code: 394720) is the result of an M.Sc. thesis of nursing, conducted with the cooperation of Isfahan University of Medical Sciences and Neyshabur University of Medical Sciences. Also, we would like to thank dear Mrs. Orouji for her contribution as statistical analyst in this project.

\section{Conflict of Interest:}

There is no conflict of interest to be declared.

Authors' contributions:

All authors contributed to this project and article equally. All authors read and approved the final manuscript. 


\section{References:}

1) Missler M, Stroebe M, Geurtsen L, Mastenbroek M, Chmoun S, Van Der Houwen K. Exploring death anxiety among elderly people: A literature review and empirical investigation. Omega (Westport). 20112012; 64(4): 357-79. doi: 10.2190/OM.64.4.e. PMID: 22530298.

2) Nakagi $\mathrm{S}$, Tada $\mathrm{T}$. Relationship between identity and attitude toward death in Japanese senior citizens. J Med Invest. 2014; 61(1-2): 103-17. PMID: 24705756.

3) Hoffmann G. Basic Geriatric nursing. United States of America: Mosby; 2008: 317.

4) Ellison CG, Fan D. Daily spiritual experiences and psychological well-being among US adults. Social Indicators Research. 2008; 88(2): 247-71. doi: 10.1007/s11205-007-9187-2.

5) Borg C, Fagerström C, Balducci C, Burholt V, Ferring D, Weber G, et al. Life satisfaction in 6 European countries: the relationship to health, self-esteem, and social and financial resources among people (aged 6589) with reduced functional capacity. Geriatr Nurs. 2008; 29(1): 48-57. doi: 10.1016/j.gerinurse.2007.05.002. PMID: 18267177.

6) Cohen AB, Pierce JD, Chambers J, Meade R, Gorvine BJ, Koenig HG. Intrinsic and extrinsic religiosity, belief in the afterlife, death anxiety, and life satisfaction in young Catholics and Protestants. Journal of Research in Personality. 2005; 39(3): 307-24. doi: 10.1016/j.jrp.2004.02.005.

7) Lyke J. Associations among aspects of meaning in life and death anxiety in young adults. Death studies. 2013; 37(5): 471-82. doi: 10.1080/07481187.2011.649939. PMID: 24517566.

8) Pampel FC. Rights of the elderly: Infobase Publishing; 2008.

9) Nelson-Becker H, Nakashima M, Canda ER. Spiritual assessment in aging: A framework for clinicians. Journal of Gerontological Social Work. 2006; 48(3-4): 331-47. doi: 10.1300/J083v48n03_04. PMID: 17210536.

10) Lehto RH, Stein KF. Death anxiety: an analysis of an evolving concept. Res Theory Nurs Pract. 2009; 23(1): 23-41. doi: 10.1891/1541-6577.23.1.23. PMID: 19418886.

11) Kim SY. Effects of Death Anxiety and Meaning of Life on Somatization of Grandparent Raising Grandchildren. J Korean Acad Nurs. 2015; 45(2): 262-70. doi: 10.4040/jkan.2015.45.2.262. PMID: 25947188

12) Brown AJ, Shen MJ, Ramondetta LM, Bodurka DC, Giuntoli RL, Diaz-Montes T. Does death anxiety affect end-of-life care discussions? Int J Gynecol Cancer. 2014; 24(8): 1521-6. doi: 10.1097/IGC.0000000000000250. PMID: 25188890.

13) Koenig H, King D, Carson VB. Handbook of religion and health. Oup Usa; 2012.

14) Mansurnejad Z, Kajbaf M. The relationship of religious orientation (intrinsic, extrinsic) and gender with death anxiety among students. Research in Cognitive and Behavioural Science. 2012; 2(1(2)): 55-64.

15) Dezutter J, Soenens B, Luyckx K, Bruyneel S, Vansteenkiste M, Duriez B, et al. The role of religion in death attitudes: Distinguishing between religious belief and style of processing religious contents. Death Stud. 2009; 33(1): 73-92. doi: 10.1080/07481180802494289. PMID: 19140293.

16) Henrie J, Patrick JH. Religiousness, religious doubt, and death anxiety. Int J Aging Hum Dev. 2014; 78(3): 203-27. doi: 10.2190/AG.78.3.a. PMID: 25265678.

17) Subaşı F, Hayran O. Evaluation of life satisfaction index of the elderly people living in nursing homes. Arch Gerontol Geriatr. 2005; 41(1): 23-9. doi: 10.1016/j.archger.2004.10.005. PMID: 15911035.

18) Meléndez JC, Tomás JM, Oliver A, Navarro E. Psychological and physical dimensions explaining life satisfaction among the elderly: A structural model examination. Arch Gerontol Geriatr. 2009; 48(3): 291-5. doi: 10.1016/j.archger.2008.02.008. PMID: 18359108 .

19) Skarupski KA, Fitchett G, Evans DA, Mendes de Leon CF. Race differences in the association of spiritual experiences and life satisfaction in older age. Aging Ment Health. 2013; 17(7): 888-95. doi: 10.1080/13607863.2013.793285. PMID: 23627686, PMCID: PMC4545598.

20) Angelini V, Cavapozzi D, Corazzini L, Paccagnella O. Age, health and life satisfaction among older Europeans. Soc Indic Res. 2012; 105(2): 293-308. doi: 10.1007/s11205-011-9882-x. PMID: 22207782, PMCID: PMC3228960.

21) Moore G. The relationship between religious orientation, coping style, and psychological health on death anxiety and life satisfaction. 2013.

22) Saini P, Patidar AB, Kaur R, Kaur M, Kaur J. Death Anxiety and Its Associated Factors among Elderly Population of Ludhiana City, Punjab. Indian Journal of Gerontology. 2016; 30(1).

23) Aliakbari Dehkordi M, Oraki M, Barghi irani Z. Relation betweereligious orientation with anxiety about death, and alienation in aged peoples (seniors) in Tehran. 2011; 1(2): 140-59. 
24) Azaiza F, Ron P, Shoham M, Gigini I. Death and dying anxiety among elderly Arab Muslims in Israel. Death Stud. 2010; 34(4): 351-64. doi: 10.1080/07481181003613941. PMID: 24479192.

25) Mahboub M, Ghahramani F, Shamohammadi Z, Parazdeh S. Relationship between daily spiritual experiences and fear of death in hemodialysis patients. Journal of Biology and Today's World. 2014; 3(1): 7-11. doi: 10.15412/J.JBTW.01030102.

26) Wink P. Who is afraid of death? Religiousness, spirituality, and death anxiety in late adulthood. Journal of religion, spirituality \& Aging. 2006; 18(2-3): 93-110. doi: 10.1300/J496v18n02_08.

27) Portal Moreno R, de la Fuente Solana EI, Aleixandre Rico M, Lozano Fernández LM. Death anxiety in institutionalized and non-institutionalized elderly people in Spain. Omega (Westport). 2008-2009; 58(1): 61-76. doi: 10.2190/OM.58.1.d. PMID: 19112875. 